Daisy Benson and Selene Colburn

\title{
Party photo phenomenon Students collaborate to promote reference services
}

$\mathbf{T}$ he University of Vermont (UVM) Libraries recently introduced a student-centered campaign to promote our Ask a Librarian services. Using a collaborative design and social networking tools, the resulting messages meet our student user population in the places they frequent.

\section{From almost famous to always famous}

In 1968, Andy Warhol predicted that, "everyone will be world-famous for 15 minutes." Today, placing a time limit on the democratization of fame already seems an antiquated notion. Anyone who can sit in front of a computer can instantly publish writing, images, and sound and video files to a global audience. The result is a kind of constant low-level fame in which anyone can partake.

In a recent article in New York Magazine, Emily Nussbaum observes that college- and high school-aged young adults who have grown up interacting with tools such as blogs, social networking sites, and streaming audiovisual files "think of themselves as having an audience." Nussbaum describes her exchange with a student at Columbia, who has been blogging since she was 13 :

Lately she's compelled by a new aspect of her public life, what she calls, with a certain hilarious spokeswoman-forthe-cause affect, the "party-photo phenomenon." [she] clicks to her Facebook profile, which features 88 photos. Some are snapshots. Some are modeling poses she took for a friend's portfolio. And then there are her MisShapes shots: images from a popular party in Tribeca, where photographers shoot attendees against a backdrop..."To me, or to a lot of people, it's like, why go to a party if you're not going to get your picture taken?"1

\section{From advertisement to campaign}

In the spring of 2007, the UVM Libraries decided to place an advertisement in the student handbook. Previous library outreach efforts had often focused on wholesale promotion of collections and services, and had featured images that depicted exactly the kinds of objects and activities associated with libraries: students and librarians gathered around computers, pointing with enthusiasm at something flashing on the screen; stacks of books demonstrating a range of titles; computer terminals; even cups of coffee.

The student handbook already contained good general information about the libraries, so we chose to experiment with promoting a specific service. From our 2005 LibQUAL survey results, we knew that users who interacted with reference librarians were extremely satisfied. At the same time, data indicated that patrons were confused about how to locate, access, and best use library resources. Reference transactions could bear increased demand in a way that other services could not. Finally, we were about to introduce a new iteration of chat reference services targeted at our undergraduate population. All this made UVM's package of

Daisy Benson is reference and instruction librarian, e-mail: daisy.benson@uvm.edu, and Selene Colburn is assistant dean of libraries for external relations, email: selene.colburn@uvm.edu, at the University of Vermont

๑) 2008 Daisy Benson and Selene Colburn 
Ask a Librarian services an ideal subject for promotion.

We wanted a student-centered approach that engaged our users as collaborators. In light of data asserting students' independent natures, it was important to take the focus off the librarian at the end of the service and celebrate both the quest for knowledge and a loftier outcome of research: increased creativity and originality. We also wanted to play on our undergraduate population's desire to see and be seen, while echoing the look and feel of social networking sites such as Facebook and MySpace.

Our message was distilled to a single word, $a s k$, which both directed users to the appropriate services and celebrated the general spirit of inquiry that's fundamental to the UVM Libraries' mission. Students were photographed holding a simple sign proclaiming "Ask." To elicit their playfulness, we described our photo shoots as comparable to old self-service photo booths.

Recruitment techniques played on (and hopefully subverted) reality television's notion of star making by seeking students to serve as "UVM Libraries' Top Models," while emphasizing our commitment to portraying a diverse group of individuals. Text from a recruitment poster read:

The Libraries' Top Models will be: expressive, diverse, creative, all shapes and sizes, funny, passionate (and a bunch of adjectives we haven't thought of yet, because we are waiting for you to show us).

Early on in our process, we realized that the life of resulting images need not be confined to a single advertisement, but could be used to construct a campaign of some duration across media.

\section{The photo shoots}

To date we've held three photo shoots, resulting in photographs of approximately 89 students: two in the spring of 2007 at the Bailey/Howe Library's Cybercafé, and one at a student activities fair in the fall of 2007. Our first two photo shoots required very little preparation. We hung promotional posters outside the café in the library on the day of the events and posted a notice to the libraries' Web site. Students waiting in line for coffee and snacks were recruited and photographed against a simple white backdrop pinned to a nearby bulletin board. It quickly became apparent that the event itself was an important form of outreach. As participants signed release forms, we described the services they were being asked to promote, sharing the address of the Ask a Librarian Web page. Daisy Benson, assistant library faculty in the Instruction and Information Department, photographed students while chatting briefly to put them at ease. In the following weeks, a number of our "models" approached Daisy at the reference desk with questions.

At the student activities fair, we further optimized the event's outreach potential. We staffed a booth for several hours prior to the photo shoot, highlighting past images in the form of posters and handouts promoting both the upcoming photo shoot and the service itself. Even students who had no interest in being photographed left with information about how to contact reference librarians. Many students responded to the images with admiration, exclaiming "Cool!" as they recognized friends and acquaintances. Surprising numbers returned at the appointed time to get their pictures taken. After models were photographed, they were given sample promotional materials and a handout about how to view the resulting photos.

Students' genuine enthusiasm for being photographed has been widespread and impressive. When asked to participate, one

\section{Online extra}

Visit the April 2008 issue of CERL News online at www.acrl.org/c\&rlnews for a podcast interview with article authors Daisy Benson and Selene Colburn. 
young man asked with hesitation, "Will a lot of people see these?"

"Well, yes," we told him apologetically, preparing ourselves for his refusal.

"Oh, sure then," he said.

Another student responded to our request by assuring us that he was "really good at this kind of thing."

Our evolving group of models are, indeed, really good at spending time in front of the camera. They have shown a capacity for self-expression and candor that continues to astonish and inspire us.

\section{"Ask" Campaign Vehicles}

The advertisement we created for the student handbook featured 12 students and the simple text "Ask questions @ your library,” accompanied by the address for the Ask a Librarian Web page. It appeared in the fall of 2007. The advertisement was also enlarged to a poster-sized image, along with photographs of individual models, and used at orientations for faculty and graduate students.

Multiple images of the same models were used to create popular bookmarks replicating photo booth strips, with further information about

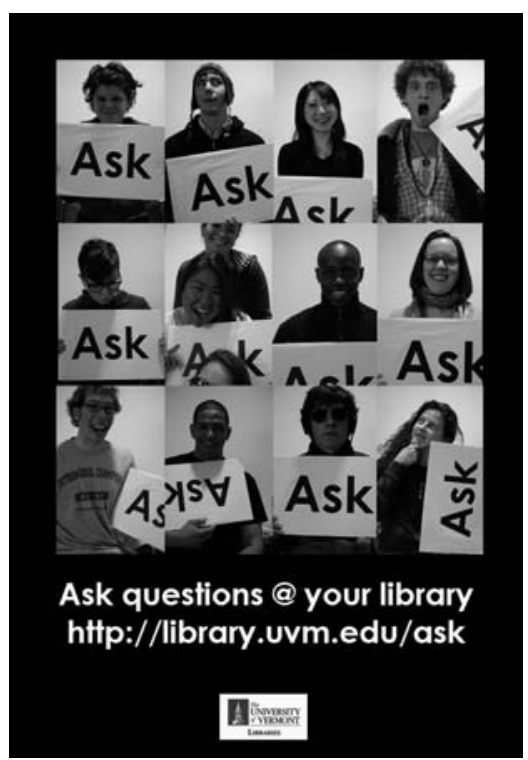

images will be incorporated into professional signage directing Bailey/Howe Library visitors to the reference desk. We're preparing to place versions of the advertisement designed for the handbook in The Cynic, UVM's student newspaper, and to engage the assistance of library student workers in hanging flyers across campus at regular intervals. We're preparing to create a similar set of images depicting users of our Dana Medical Library, so the campaign can be adapted to promote their parallel services.

\section{The"Ask" Campaign Goes $\mathbf{2 . 0}$}

In addition to the more traditional communication vehicles described above, social networking sites are an integral part of this project. We knew from the outset that we wanted to be able to share photographs with our models and their friends. The participants' requests to see the images and obtain copies furthered our commitment. We use both Flickr and Facebook as tools to facilitate this process.

Flickr is a photo sharing utility that allows its users to store and share photographs. Additional features, such as the ability to comment upon, tag, and mark images as Ask a Librarian services on the reverse.

Postcard-sized advertisements were designed for tabletops in the popular dining areas of UVM's new student center. These featured images from the student activities fair photo shoot and appeared only days later. We were able to tell models about this use of the images both at the shoot itself and in a follow-up e-mail they received almost immediately, thus capitalizing on their interest.

Images have also appeared on a flat screen in the Bailey/Howe Library lobby, and we're hoping to syndicate these to similar presentations in other campus facilities, such as residential and dining spaces, the student center, and administrative buildings. Some of the favorites, add a layer of social interactivity. We have posted the majority of the photos to Flickr ${ }^{2}$ (excluding a handful of unflattering shots) and shared the site with models via email notification. This allows students to easily download images in the size of their choice, which they have put to some surprising uses of their own. Flickr is not simply a place to store the images, it is another channel by which to promote the Ask services.

With more than 16,000 members in its UVM network, Facebook cannot be ignored as a communication vehicle. Facebook is a social networking site that allows users to create profiles; connect to friends; send messages; form groups around common interests; and share 
links, photographs, event information, and notes.

Prior to the student activities fair, we created a Facebook group called UVM Libraries' Top Models and used Facebook's event feature to ensure that the upcoming photo shoot would appear in the UVM network calendar. When students were photographed at the fair, we invited them to join the Facebook group to see examples of how their images were used and to learn about future events. From the group, we were able to upload examples of print advertisements, further promote the Ask a Librarian Web page, and post links to Flickr photo sets.

The link to the student activities fair photos posted on Flickr briefly became one of the most popular posted items in the UVM network, as student models shared it with their large collections of friends. Students who have joined the Facebook group have downloaded "Ask" campaign images into their Facebook albums, occasionally even using them as profile pictures. They have tagged themselves and one another in images and commented on the photos. One model commented on a photo of herself with some friends, "Awww look how cute we are! We're such good models." And another commented on a photo of herself, "I'm a model! (For the library)." All of their Facebook friends are notified of these actions via the newsfeed that serves as each user's customized homepage, resulting in a second wave of usergenerated marketing for the Libraries and the "Ask" campaign.

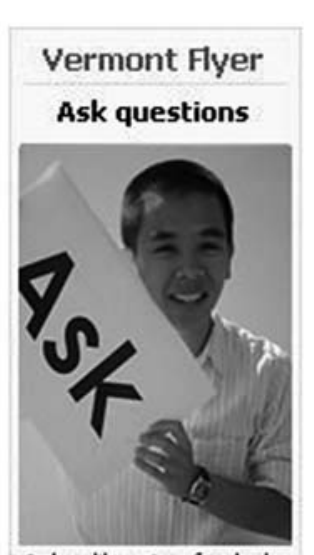

Ask a librarian for help to save time and reduce frustration. Join the UVM Libraries' Top Models group to learn more.

Posted by Selene Colburn

[ create | see all ] Share +
We used the cost-effective flyer feature to design mini-advertisements that display as UVM student users are navigating through Facebook. The flyers ran over a period of six days, across two weeks, were displayed 45,000 times to current UVM students, and featured a unique image each day, accompanied by text that read "Ask Questions. Ask a librarian for help to save time and reduce frustration. Join the UVM Libraries' Top Models group to learn more." The flyers linked to the Ask a Librarian Web page.

\section{Conclusion}

We are currently logging the appearance and duration of each new iteration of "Ask" images and messages, so we can cross-reference these with reference transaction statistics for the fall 2007 semester as a means of measuring success and are preparing a survey to ascertain what directed users to reference services.

As the UVM Libraries move toward increasingly strategic communications, the "Ask" campaign is an important pilot to help us discover what resonates with student users and which communication vehicles have the most impact. Without the participation and creativity of our students, such a campaign could not exist.

\section{Notes}

1. Emily Nussbaum, "Say Everything," New York Magazine, February 12, 2007: 29.

2. UVM Libraries Top Models Flickr sets, www.flickr.com/photos /uvmlibraries/sets. $\boldsymbol{n}$ 